\title{
Snippets from the worldwide web
}

Sri Lanka Journal of Child Health, 2010; 39: 146-147

\section{CSF White Blood Cell Counts in Febrile Infants Lower Than Published Values}

Cerebrospinal fluid (CSF) white blood cell (WBC) counts in febrile infants without evidence of infection are lower than reported in paediatric references, researchers from the University of Utah report in the September 1 online issue of The Journal of Pediatrics. Authors describe the CSF profiles of 823 febrile infants with negative bacterial culture test results of blood, urine, and CSF and negative test results for enterovirus with PCR. "The data was derived from infants 1-90 days of age with fever of at least $38^{\circ} \mathrm{C}$," Dr. Byington said. "Infants who had laboratory-confirmed bacterial or enteroviral infections that could elevate CSF WBC counts and protein levels were excluded." Mean CSF WBC counts were 6.1/cubic $\mathrm{mm}$ during month 1 of life, 3.1/cubic mm during month 2, and 3.0/cubic mm during month 3. Even when statistical outliers were included, the range for CSF WBC count for infants in the first month was 0 to $20.5 /$ cubic $\mathrm{mm}$, lower than published norms. When outliers were excluded, the range for CSF WBC count had an upper limit of 18 /cubic $\mathrm{mm}$, again lower than the published reference values of up to $22 /$ cubic $\mathrm{mm}$.

http://www.medscape.com/viewarticle/729955

\section{OTC Paediatric Dosing Cups Often Marked to Give Inaccurate Doses}

Cups to measure paediatric liquid medication dose, commonly sold with over-the-counter medications, often are marked inaccurately, potentially providing a larger dose than is intended or recommended, according to research presented here at the American College of Emergency Physicians 2010 Scientific Assembly. Researchers independently measured 2.5 and $5.0 \mathrm{~mL}$ doses of water and medication according to markings on 7 over-the-counter medication dose cups, and then poured the contents into a standard $10 \mathrm{~mL}$ graduated cylinder and recorded the measurement. Overall, the results on the accurate cylinder showed measurements that were an average of $0.33 \mathrm{~mL}$ greater than the measuring cup $(95 \%$ confidence interval $[\mathrm{CI}], 0.15-0.52 ; P=.0012)$. When water was tested against the cylinder for all 7 dosing cups, the cylinder measurement was $0.63 \mathrm{~mL}$ more than the dosing cup (95\%CI $0.42-0.86 ; P<.0001)$.

http://www.medscape.com/viewarticle/729974
Vitamin D Supplements May Not Increase Bone Density in Healthy Children

Use of vitamin D supplements may not improve bone density in healthy children with normal vitamin D levels, but vitamin D-deficient children may benefit, according to the results of a systematic review reported online October 6 in the Cochrane Database of Systematic Reviews.

http://www.medscape.com/viewarticle/729952

\section{Ligament Reconstruction Reduces Kneecap Dislocations in Children With Patellar Instability}

Children with patellar instability have good shortterm results after reconstruction of the medial patella-femoral ligament (MPFL), according to a study presented here at the American Academy of Pediatrics 2010 National Conference and Exhibition. MPFL reconstruction has been well studied in adults with patellar instability, but use of the technique is controversial in children. "Historically, there have not been a lot of great options [for children with patellar dislocations]," Jennifer Weiss, MD, assistant professor of orthopaedics at Children's Hospital Los Angeles, California, who presented the study findings, told Medscape Medical News.

http://www.medscape.com/viewarticle/729903

\section{Indoor Microbes Protect Against Asthma in Some Countries, but Not All}

Exposure to indoor mould and endotoxin seems to protect children against asthma and rhinitis in Germany, but not in The Netherlands, a new paper reports. "Health impacts of domestic microbial exposure on allergic disorders are complex," said lead author Dr. Christina Tischer in email to Reuters Health. "Even though there was a standardized exposure measurement and assessment in three similar birth cohorts of the same age, health consequences were different between the German and the Dutch studies."

http://www.medscape.com/viewarticle/730171

\section{Family Dog Tied to Lower Eczema Rates in At- Risk Kids}

Young children with a family history of allergies may be less likely to develop eczema if they live 
with a dog starting in infancy, a new study suggests. On the other hand, researchers found, living with a cat may increase those odds -- but only among children who have a specific sensitivity to cat allergen.

http://www.medscape.com/viewarticle/730452

\section{Avoid Protease Inhibitors When Treating Both $H I V$ and $T B$ in Children}

While treating children with HIV-TB co-infection, concurrent use of protease inhibitors and antituberculosis treatment may increase the risk of HIV treatment failures, a study from South Africa shows. HIV virologic suppression rates were lower with protease inhibitor-based regimens as compared to non-nucleoside reverse transcriptase inhibitors (NNRTI).

http://www.medscape.com/viewarticle/730967

\section{Drug Companies Influence Prescribing, Study Finds}

Doctors tend to prescribe drugs that pharmaceutical companies promote to them and patients end up paying more but not always getting the most suitable medicines, researchers reported on Wednesday. An analysis of 58 studies in several countries found that information from drug companies influenced the decisions doctors made, and not necessarily in a positive way.

\section{http://www.medscape.com/viewarticle/730927}

\section{Metformin Can Slow Precocious Puberty in Girls}

Metformin can delay menarche in girls with early onset of puberty and help them attain greater height, a new study suggests. But whether or not to exercise this option is controversial.

http://www.medscape.com/viewarticle/730862

\section{Fructose Intolerance, Malabsorption a Common Culprit in Paediatric Abdominal Pain}

Fructose intolerance or malabsorption is a common but often undetected cause of recurrent abdominal pain in children, but the problem can be effectively resolved with a low-fructose diet, according to research presented here at the American College of Gastroenterology 2010 Annual Scientific Meeting and Postgraduate Course.

http://www.medscape.com/viewarticle/730845

\section{Maternal Herpes Suppression Does Not Prevent Neonatal Transmission}

A practice bulletin of the American Congress of Obstetricians and Gynecologists (ACOG; Obstet Gynecol. 2007 Jun;109(6):1489-1498) recommends offering antiviral drugs during the last 4 weeks of gestation for women who have a history of recurrent genital herpes - the idea being that the drugs will prevent transmission of the virus from mother to newborn. However, said Swetha Pinninti, MD, fellow in paediatric infectious diseases at the University of Alabama at Birmingham: "Maternal antiviral suppressive therapy during pregnancy does not prevent herpes disease in the newborn."

http://www.medscape.com/viewarticle/731292

\section{Preeclampsia Protects Against Retinopathy in} Preterm Infants

Among the many disadvantages of preeclampsia, Brazilian researchers have found one beneficial effect: it protects preterm infants against severe retinopathy of prematurity (ROP). It's likely that women with preeclampsia are in an antiangiogenic state and that an "antiangiogenic factor protects very premature newborns from severe ROP,"

http://www.medscape.com/viewarticle/731152

\section{Neonatal CBCs More Informative a Few Hours After Birth}

In newborns with suspected sepsis, don't start antibiotics on the basis of complete blood counts (CBCs) done less than four hours after birth, researchers say -- because these numbers improve "dramatically" over the first few hours of life. "This study shows that $\mathrm{CBCs}$ done in the first hour after birth are not helpful at predicting infection. Decisions about antibiotics in these youngest newborns should be made based on maternal risk factors and newborn signs and symptoms, not the CBC," said lead author Dr. Thomas B. Newman.

http://www.medscape.com/viewarticle/731125

\section{B J C Perera \\ Joint Editor}

